\title{
A new locality of the rare snail Plectostoma tonkinianum (Dautzenberg \& Fisher, 1905) (Gastropoda: Caenogastropoda: Diplommatidae) in Southern Vietnam
}

\author{
Ivaylo Dedovi, Manh Quang Vu',3, Nam Hai Tran²
}

1 Institute of Biodiversity and Ecosystem Research, Bulgarian Academy of Sciences, 2 Gagarin Street, 1113 Sofia, Bulgaria,idedov@gmail.com (corresponding author)

2 Hanoi National University of Education (HNUE), 136 Xuan Thuy Rd, DHSP Cau Giay, Hanoi, Vietnam

3 Ho Chi Minh City University of Food Industry, 140 Le Trong Tan St, Tan Phu, Ho Chi Minh City, Vietnam, vqmanh@gmail.com

\begin{abstract}
We confirm the occurrence of the rare species Plectostoma tonkinianum (Dautzenberg \& Fisher, 1905) in Vietnam with a new georeferenced locality.
\end{abstract}

Keywords: Plectostoma, new records, Southeastern Indochinese Peninsula

\section{Introduction}

In old literature $\left(19^{\text {th }}\right.$ and beginning of $20^{\text {th }}$ centuries $)$ many of the published species records are from localities whose names are presently changed. Additionally, because of borders changing, many of the old areas, such as "Cochinchina", "Annam", "Tonkin", today are divided in different countries (Schileyko, 2011). For example, the French protectorate "Tonkin", from where the type locality of Plectostoma tonkinianum (Dautzenberg \& Fisher, 1905) is, presently covers territories in Southern China and the northern parts of Laos and Vietnam (Liew et al., 2014).

Up to now, the genus Plectostoma was assumed to be present in Vietnam with a single species $-P$. tonkinianum. Based on the analysis of the information in the old work of Dautzenberg \& Fisher (1905), Liew et al. (2014) suggests that "P. tonkinianum probably occurs in the small limestone hills in the coastal areas of the southern part of Vietnam and neighbouring Cambodia." Our finding confirms this suggestion.

Received: 11 February 2019 • Editor: Nikolay Simov

\section{Material and methods}

The material was collected via the soil-sifting procedure (Antonova et al., 2015).

The specimens are stored in the mollusc's collection of the Institute of Biodiversity and Ecosystem Research, Bulgarian Academy of Sciences, Sofia (Coll. ID 40334/9, adult specimens A-O).

\section{Results and discussion}

Plectostoma tonkinianum

(Dautzenberg \& Fisher, 1905) (Fig. 2)

Material examined: Southern Vietnam, Kien Giang Province, Kien Luong District, Binh An Commune, Ba Nui Village, area around the Mo So Cave (Fig. 1), $\mathrm{N} 10.227652^{\circ}$, E104.616249, $17 \mathrm{~m}$ a.s.1., limestone rocks, 18.IX.2018, leg. I. Dedov, N. Simov, R. Bekchiev, P. Beron, 15 adult and 11 juvenile shells. 


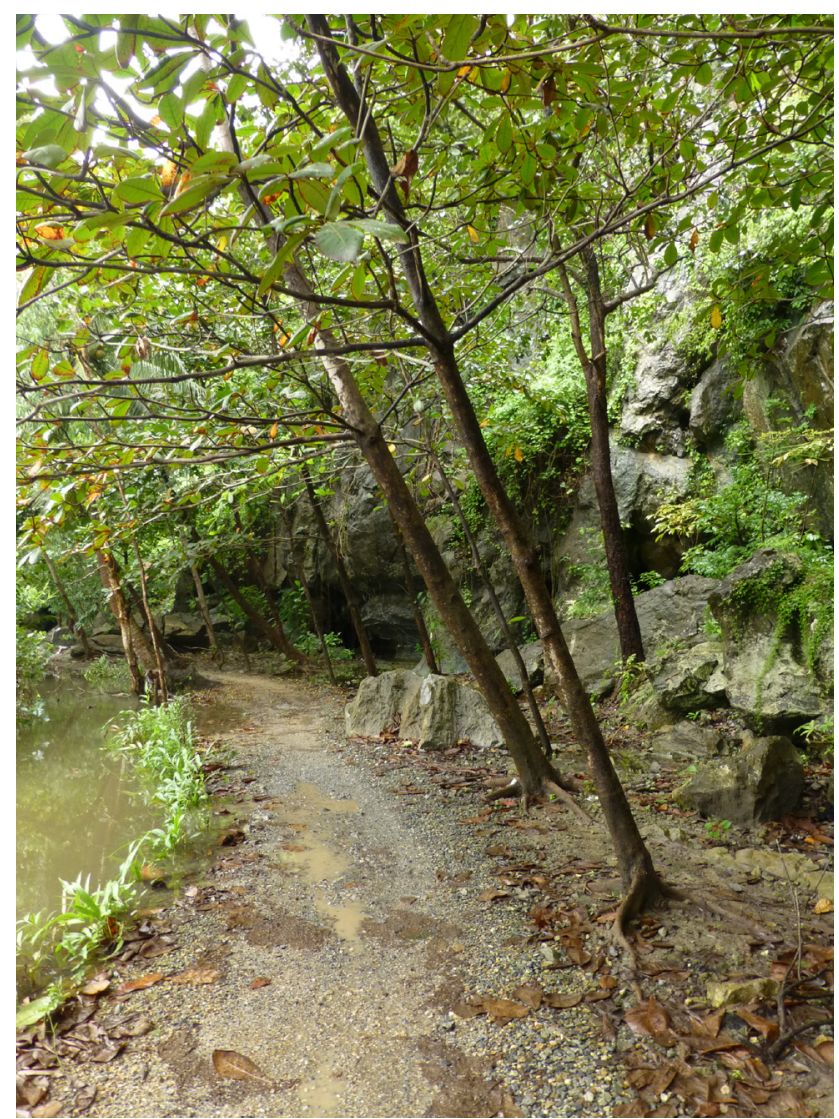

Fig. 1. Locality of the species Plectostoma tonkinianum (Dautzenberg \& Fisher, 1905), Southern Vietnam, Kien Giang Province, area of the Mo So Cave. Photo: I. K. Dedov.
The collected specimens perfectly fit to the species description, given by Liew et al. (2014, p 60-61, fig. $26 \mathrm{~A}-\mathrm{H})$ and were found in the area, suggested by the authors.

Liew et al. (2014) indicated the conservation status of the species as DD - data deficient, because of lack of information for the habitat and population status of the species. We found $P$. tonkinianum in the touristic area near the Mo So Cave. At the same time, in the neighbouring limestone hills open quarries were observed. In our opinion, in the case with such small and rare animals, inhabiting in the soil and rock crevices, touristic use of the habitat is more protective. Therefore, opening new quarries in the areas of occurrence of rare species such as P. tonkinianum, should be regulated and even forbidden.

Creating georeferenced localities and clarifying the descriptions of many of the species described from Vietnam and the whole Indochina remains an important task for the malacologists.

\section{Acknowledgments}

This study was financially supported by the Ministry of Education and Training, Code: B2016-SPH-24. We would like to thank to our colleagues N. Simov, R. Bekchiev and P. Beron for their help during the col-

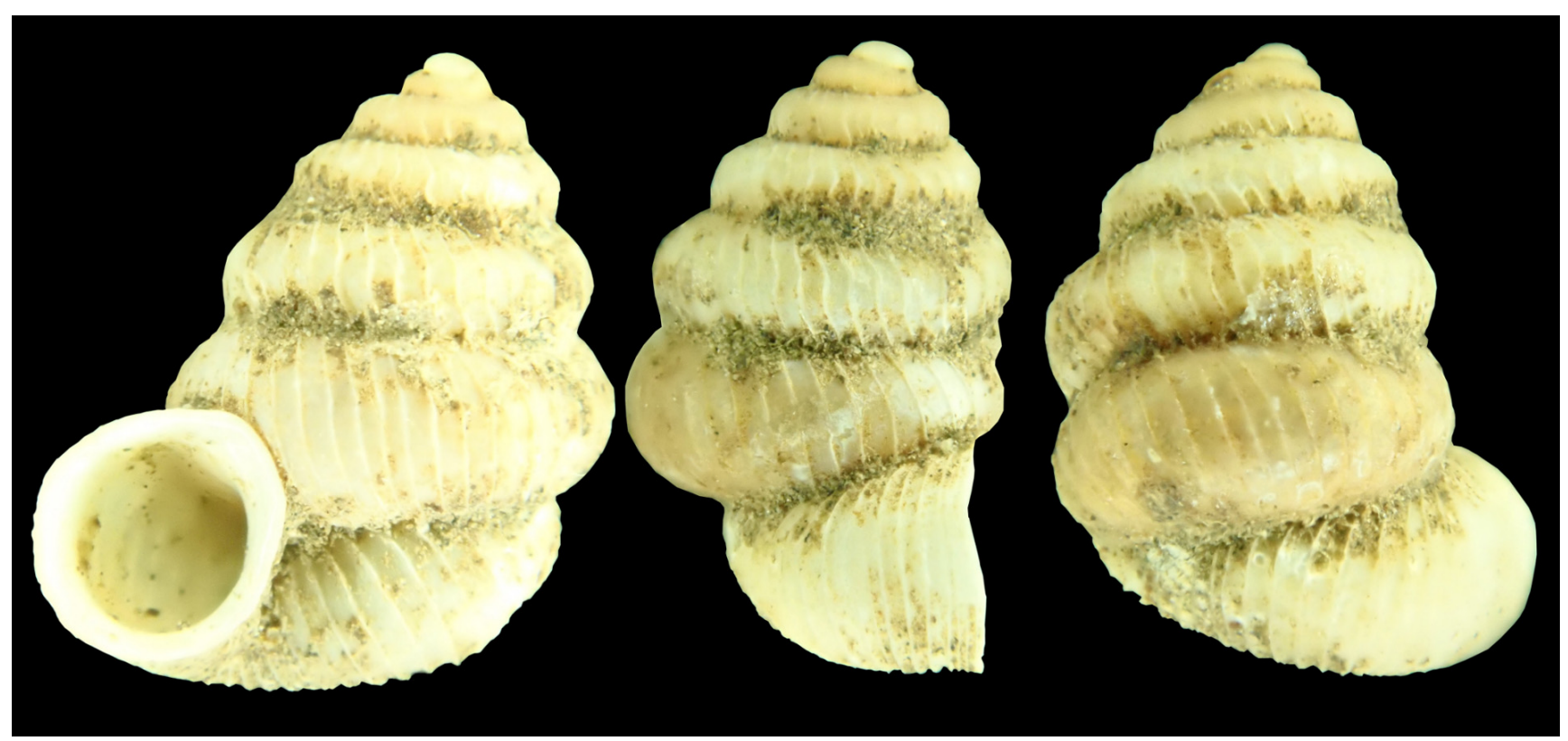

Fig. 2. Plectostoma tonkinianum (Dautzenberg \& Fisher, 1905): frontal, lateral, and posterior views of the shell. Photo: I. K. Dedov. 
lecting trip in Vietnam; to Ulrich E. Schneppat who supplied us with literature; as well as to the two anonymous reviewers for the helpful remarks.

\section{References}

Antonova V., Mitov P., Dedov I., Zapryanov L., Todorov E., Biserkov V. 2015 Inventory of Vertigo angustior Jeffreys, 1830 and Vertigo moulinsiana (Dupuy, 1849) (Gastropoda: Pulmonata) from Natura 2000 Network in Bulgaria. Acta zoologica bulgarica 67 (3): 365-374.

Dautzenberg P., Fischer H. 1905 Liste des mollusques recoltes par M.H. Mansuy en Indo-Chin et au Yun- nan et description d'especes nouvelles. Journal de Conchyliologie 53: 343-471.

Liew T.S., Vermeulen J.J., bin Marzuki M.E., Schilthuizen M. 2014 A cybertaxonomic revision of the micro-landsnail genus Plectostoma Adam (Mollusca, Caenogastropoda, Diplommatinidae), from Peninsular Malaysia, Sumatra and Indochina. ZooKeys 393: 1-107. doi: 10.3897/ zookeys.393.6717

Schileyko A.A. 2011 Check-list of land pulmonate molluscs of Vietnam (Gastropoda: Stylommatophora). Ruthenica 21 (1): 1-68. 